\title{
Violencia y devoción: acercamiento etnográfico a los barrios de una comunidad maya de Campeche ${ }^{1}$
}

\author{
David DE Ángel GARCíA \\ Centro Peninsular en Humanidades y Ciencias Sociales, UNAM (México) \\ corle_spck@yahoo.es
}

Recibido: 17 de mayo de 2012

Aceptado: 9 de julio de 2013

\section{RESUMEN}

El presente texto, de carácter esencialmente descriptivo, trata de ser una primera aproximación a los espacios intracomunitarios y a las unidades intermedias que en ellos funcionan en una comunidad indígena del mexicano estado de Campeche. Si tradicionalmente las etnografías sobre la etnia maya peninsular han presentado a la comunidad como unidad mínima de análisis, lo que aquí pretendo es descender ese peldaño para situar el foco etnográfico sobre aquellos espacios denominados «barrios». Para ello, basándome en datos de campo obtenidos de primera mano en la comunidad maya de Nunkiní (Campeche), me centro en dos cuestiones principales. En primer lugar, recurriendo a la tradición oral local, trato de indagar en los orígenes históricos que explican la enraizada división y enconada enemistad que se ha dado entre el norte y el sur de la población. Se ofrece, además, un somero acercamiento a las capillas y a las «sociedades» cívico-religiosas que se han formado en torno a ellas con el fin de festejar a los santos epónimos de los barrios, pues en torno a ellos se erige y reproduce un sentimiento de pertenencia vinculado a un espacio intracomunitario determinado.

Palabras clave: Etnografía, mayas peninsulares, barrios, «rumbos», capillas, santos.

\section{Violence and Devotion: Ethnographic Rapprochement to the Neighborhoods of a Campeche Mayan Community}

\begin{abstract}
This paper, essentially descriptive in nature, tries to be a first approach to intraspaces in an indigenous community of the Mexican state of Campeche. If traditional ethnographies on the Mayan Peninsula have considered the community as the minimum unit of analysis, what I intend is to focus on those areas ethnographic called «neighborhoods» (barrios). To do this, based on field data obtained from first-hand community Nunkiní Maya (Campeche), I focus on two main issues. First, using local tradition, I try to explore the historical origins that explain the division and bitter enmity that has occurred between the northern and southern populations. I offer also a superficial approach to chapels and the civic-religious societies that have emerged around them to celebrate the saint that each neighborhood has creating a special belonging feeling among neighbors.
\end{abstract}

Key words: Ethnography, Mayan peninsula, neighborhoods, «courses», chapels, saints.

Sumario: 1. Introducción. 2. Primero fueron el norte y el sur. 3. «La época de la violencia»: luchas entre el norte y el sur. 4. Viejos santos, nuevas capillas: el surgimiento de los barrios. 5. A modo de punto y seguido. 6. Referencias bibliográficas.

\section{Introducción}

A decir de los propios vecinos de Nunkiní (población ubicada en la región del Camino Real en su vertiente campechana), son siete los «barrios» o «colonias», con sus

1 La totalidad de la información contenida en este artículo ha sido obtenida de primera mano a través de la realización de diversas estancias de campo en la población de Nunkiní, a la cual arribé por primera vez en mayo de 2006. La temática y los datos presentados se encuadran en el marco del proyecto de investigación «Capillas, santos y fieles: religión e identidades barriales en una comunidad maya de Campeche», que desde septiembre de 2010 vengo desarrollando en el Centro Peninsular en Humanidades y Ciencias Sociales de la UNAM en Mérida, Yucatán. 


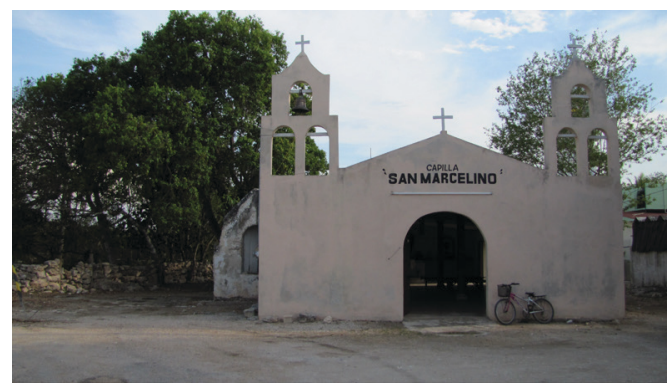

Figura 2: Un momento del rezo nocturno que se desarrolla en la capilla de san Martín durante nueve noches consecutivas. Las novenas son la principal celebración religiosa que se realiza en honor a los santos.
Figura 1: La capilla de San Marcelino en el barrio del mismo nombre. A su izquierda todavía conserva el antiguo «olatorio» que albergaba la cruz que dio origen a la capilla $\mathrm{y}$ al barrio.

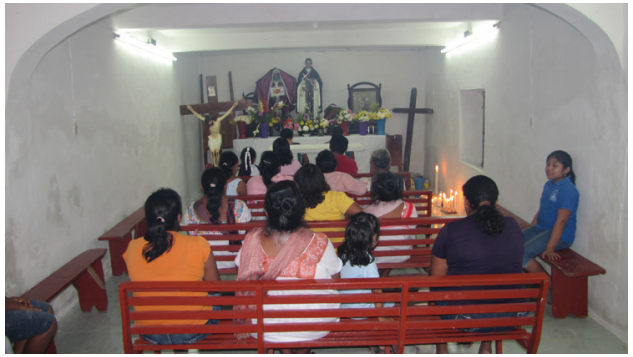

respectivas capillas y santos epónimos, que conforman actualmente la geografía de esta localidad, albergando en ellos a la gran mayoría de sus más de 6.000 habitantes². Así, en el rumbo norte de la comunidad se asientan los barrios de San Román, San Francisco y La Guadalupe, mientras que los de San Martín, San Isidro, el Divino Niño (también conocido como «la Colonia») y San Marcelino, más comúnmente llamado Gato Negro, lo hacen por el sur. A las mencionadas siete capillas que dan nombre a estas colonias, habría que sumar una octava: la de san José; ubicada también en el sur de la población, dentro de los límites del barrio del Gato Negro, y sobre la cual parece no existir acuerdo entre los vecinos respecto a si conforma o no una barriada diferenciada de las que ya han sido referidas. Como veremos más adelante, las capillas y las devociones construidas en torno a sus santos patrones han sido indispensables para la posterior fundación y reconocimiento popular de los barrios actuales, la gran mayoría de reciente creación. Y es que, según los testimonios recopilados, parece ser que no fue hasta que se organizaron los vecinos cuando se erigieron las actuales capillas (o «iglesitas», como las nombran los fieles, pues reproducen el patrón arquitectónico de la iglesia local pero a menor escala) en diversos terrenos baldíos repartidos por los rumbos del pueblo, y, en torno a ellas, comenzaron a organizar celebraciones religiosas, y fue hasta entonces que los espacios residenciales colindantes adoptaron definitivamente el nombre del santo al que se dedica el edificio y la fiesta (Figuras 1 y 2 ).

Sin embargo, y a pesar de su más que notable presencia numérica en la actualidad, los barrios de Nunkiní no parecen desempeñar a día de hoy ninguna función de carácter político-administrativa dentro del gobierno de la localidad, así como tampoco cuentan con ningún representante ante las autoridades municipales. Únicamente los «patrones» y los «socios» que conforman las sociedades religiosas encargadas de

2 Según los datos arrojados por el censo del INEGI en el año 2005, la población total de Nunkiní superaba por muy poco los 6.000 habitantes, de los cuales prácticamente el $90 \%$ eran hablantes de lengua maya, y una cifra muy similar declaraban que profesaban la religión católica. De hecho, la presencia en la población de grupos evangélicos o protestantes está restringida a unas pocas familias, siendo lo anterior motivo de orgullo para los vecinos, que se declaran a ellos mismos y a su comunidad como muy devotos de su santo patrón, y muy apegados a sus formas tradicionales de festejarlo. 
festejar a los santos epónimos de cada barrio parecen tener cierto «poder» dentro de estos espacios intracomunitarios. Poder que se restringe al ámbito de la capilla (la necesidad o no de acometer ampliaciones, reformas, comprar de muebles, etc.), y a la toma de decisiones vinculadas con el funcionamiento y la organización de la «sociedad» del santo, y la naturaleza de las celebraciones que se le dedican al santo barrial, tales como las fechas en que tendrá lugar la fiesta o el tipo de festejos y de atracciones que se contratarán para darle lucimiento. Constatamos así como en torno a lo religioso parece gravitar la existencia de los actuales barrios, encontrando en la figura del santo patrón de cada barrio, y en el culto que a él se le brinda, el origen y la principal razón de su existencia. Pero antes de adelantar acontecimientos, repasemos brevemente algo de los antecedentes de estas formaciones territoriales intracomunitarias en el ámbito maya peninsular (Figura 3).

Quizá por ser de muy reciente creación en comparación con aquellos barrios o parcialidades con nombres de santos hispanos que fueron surgiendo en las antiguas capitales de los cacicazgos prehispánicos, a raíz de las reducciones de poblaciones aledañas llevadas a cabo en ellos

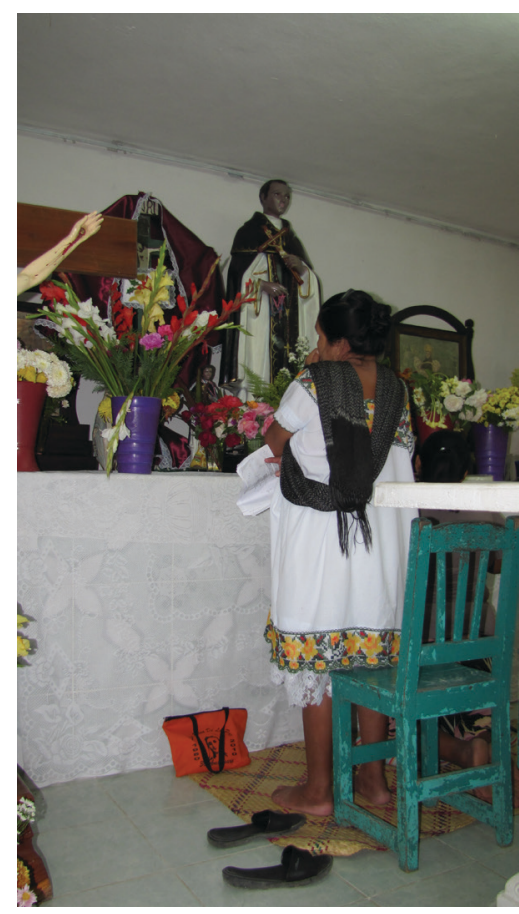

Figura 3: Una rezadora contratada ex profeso para «cantar» los rezos en honor a san Martín con motivo de la celebración de su novena en el mes de diciembre. por los conquistadores hispanos (Farris 1992: 163) ${ }^{3}$, no existe en los actuales barrios de Nunkiní el más mínimo rastro de las añejas atribuciones político-administrativas que, según el historiador Sergio Quezada (1993: 64, 1997: 41-47), poseían las parcialidades o cuchteelo' $o b$ que conformaban las principales poblaciones indígenas de la península de Yucatán desde época prehispánica ${ }^{4}$. Mucho menos he podido localizar en ellos a los sucesores de los ah kulo'ob, vetustos jefes de estas parcialidades precolombinas, quienes eran elegidos por los cabezas de familia que las integraban, para que representaran a cada parcialidad ante el batab del pueblo (Quezada 1997: 41), los cuales, a decir de Fray Diego de Landa, eran «muy obedecidos y estimados» y «su palabra era escuchada cuando el batab impartía justicia». Para otros autores, por el

\footnotetext{
3 En 1552, las Ordenanzas del oidor Tomás Pérez Medel establecieron que los indígenas de Yucatán debían reunirse en pueblos, dentro de la traza que se les diera, hacer casas juntas de obra duradera, no sembrar milpas dentro del pueblo y no tener arboledas, sino todo muy limpio» (Quintal et al. 2003a: 302).

${ }^{4}$ El mencionado autor refiere también que el cuchteel estaba «integrado por un conjunto de casas, cada una de las cuales agrupaba hasta seis jefes de familia con sus respectivas proles» (Quesada 1997: 41), aspecto que comparte con los barrios contemporáneos. Sin embargo, el mayor peso que éstos tuvieron antes del arribo de los españoles queda patente en el hecho de que los cuchteelo'ob «eran tanto una unidad administrativa, encargada de proveer fuerza de trabajo de productos a la élite, como una entidad militar, pues era el sustento de los ejércitos en tiempo de guerra» (1997: 41).
} 
contrario, estos antiguos «caudillos» de las parcialidades en los albores de la época colonial eran designados por el propio batab de cada pueblo, quien los nombraba como sus representantes en cada barrio, lo que a su vez permitía a estos personajes aglutinar cierta «autoridad independiente [a la del cacique] en el interior de la parcialidad o barrio a su cargo» (Bracamonte y Solís 1996: 67) .

Tampoco son visibles a día de hoy en Nunkiní aquellos «principales» de barrio que a medidos del siglo XVII, según reportaba el fraile franciscano Diego López de Cogolludo en su ya clásica Historia de Yucatán, eran los responsables de «procurar todo lo que se ofrecía en lo material y en lo espiritual», de que las mujeres y hombres concurrieran a misa los domingos y fiestas de guardar, y de ejecutar las órdenes del gobernador del pueblo (López de Cogolludo 1957: Lib. IV, Cap. XVII) ${ }^{6}$. Desconozco si estos «principales» eran los mismos individuos a los que hace referencia Miguel Ángel Bartolomé (1988: 104), los cuales eran nombrados por el cacique del pueblo, recibiendo el antiguo título de chun tan, para encargarse de recolectar el tributo y las limosnas correspondientes a su parcialidad ${ }^{7}$.

Sin embargo, para ser justos, debemos asentar que resulta lógico que en Nunkiní no se encuentren restos de todos estos cargos que durante la Colonia se encargaron de administrar y gobernar los barrios, ya que la aparición de éstos únicamente se dio en aquellas poblaciones principales que desde la época prehispánica fungían como capitales de cacicazgo y eran el lugar de residencia del batab. Así, por ejemplo, el cacicazgo de los Ah Canul, al cual pertenecía Nunkiní, tenía su capital en la población de Calkiní, en la cual los primeros evangelizadores levantaron un monumental convento franciscano. Fue en esta población donde se llevó a cabo la reducción o concentración de los habitantes de muchas poblaciones menores aledañas (como estancias, rancherías o milperías), lo que provocó que brotaran nuevas subdivisiones al interior de Calkiní que adquirieron el calificativo de barrios ${ }^{8}$. Cada uno de ellos recibiría un nombre propio «derivado de alguna característica del terreno o de algún santo patrono» (Bracamonte y Solís 1996: 66-67), por lo que la costumbre de utilizar nombres de santos para nombrar a los barrios parece venir de antiguo 9

\footnotetext{
5 Las principales atribuciones de estos jefes de barrio nombrados por el batab, amén de fungir como sus representantes y extender su dominio por toda la población, «consistían en vigilar el desarrollo de la cristianización, las cobranzas de tributos y las limosnas, y en general todo lo concerniente a su república» (Bracamonte y Solís 1996: 67-68).

6 Sergio Quezada, siguiendo a López de Cogolludo, reporta hasta mediados del s. XVIII la presencia en cada barrio de dos «patrones de enfermos», cuya obligación era notificar a los frailes doctrineros el momento en que una persona necesitaba los sacramentos. El cargo se rotaba semanalmente con el fin de que siempre hubiera uno de los dos en funciones, mientras que el otro se dedicaba a las labores agrícolas (Quezada 1997: 171-174). Bracamonte y Solís (1996: 68) reportan también la existencia de este cargo «al que se le entregaba una vara con una insignia religiosa y una cruz en la parte superior».

7 Bartolomé (1988: 106) refiere que con el paso del tiempo, los gobernadores coloniales españoles consideraron a este sistema como «demasiado autónomo», por lo que para agilizar la tributación de los indígenas «impusieron a los pueblos más grandes funcionarios españoles, los corregidores».

8 Historiadores de la época colonial yucateca definen estos barrios como «las nuevas subdivisiones de los pueblos que surgieron durante la segunda mitad del siglo XVI» (Quezada 1993: 68), a raíz de la reducción de las parcialidades en las poblaciones consideradas cabeceras.

9 En este sentido, Quezada refiere que para mediados del siglo XVII los pueblos más importantes de la Península estaban ya divididos en barrios «y para distinguirlos se les asignó el nombre de un santo» (1997: 171).
} 
Regresando a Nunkiní, además de los siete barrios actuales ya mencionados, existe otra subdivisión espacial y de fuerte contenido simbólico a la que no hemos hecho referencia todavía y que, como las anteriores, permite a los vecinos de Nunkiní ordenar los espacios internos de su propia comunidad. Se trata de aquella que remite a la parte nuclear del asentamiento, la cual se conoce como «el centro». Esta parte de la localidad se encuentra conformada, principalmente, por la plaza principal del pueblo, donde se encuentra la iglesia y el Palacio de Gobierno. Pero alcanza, además, las dos primeras cuadras del trazado urbano de la población, extendiéndose, incluso, hacia el norte y el oriente de ésta a los márgenes de las dos carreteras más transitadas de Nunkiní: la que atraviesa la población de este a oeste y comunica con la cabecera municipal (Calkiní), y aquella que saliendo hacia el norte conduce a la población de Halachó, en el vecino estado de Yucatán.

Como bien han apuntado otros investigadores del área peninsular, el Centro constituye «el corazón de la población» (Thompson 1974: 37). Es el espacio que representa a la comunidad en su conjunto (Quintal et al. 2003a, 2003b), pues en él se concentran tanto el Palacio Municipal y la comisaría ejidal, ambas sedes del gobierno y poder local, como el mercado y la iglesia de la población, ésta última considerada la «casa» del santo patrono de Nunkiní, san Diego de Alcalá, uno de los máximos exponentes de la identidad comunitaria. De la misma forma, es en la plaza central donde se repiten cada año, durante una semana en abril y a lo largo de todo el mes de noviembre, los diversos actos lúdicos y religiosos con que los nunkinienses conmemoran tanto el novenario como la Feria que le dedican a su santo patrón, símbolo sagrado por antonomasia de la comunidad y máximo protagonista y receptor de buena parte del complejo mítico y ritual local (de Ángel 2009, 2010) ${ }^{10}$. Se trata, a su vez, de un espacio liminal, en tanto que no forma parte de ninguno de los barrios antes mencionados, pero del que salen y en el cual desembocan los caminos que conducen a todos ellos. Asimismo es importante destacar que, a diferencia de lo que sucede en otras poblaciones, lo que se conoce como «el Centro» en Nunkiní mantiene una fuerte impronta indígena, y aunque muchos de sus actuales residentes conforman la élite económica de la población, la inmensa mayoría de ellos portan uno o los dos patronímicos de ascendencia maya ${ }^{11}$.

10 Muchos son los autores que han señalado la centralidad que ocupan las figuras de los santos patrones de las comunidades mayas peninsulares a la hora de reafirmar los lazos comunitarios y las identidades territoriales que unen indisolublemente a los individuos con sus comunidades de origen (Fernández 1995; Lizama 2007; Quintal et al. 2003a, 2003b; Ruz 2007: 300-302; Terán y Rasmussen 2005). Para un acercamiento a la multiplicidad de formas en que los santos son percibidos en el extenso mundo maya, remito al lector interesado al excelente ensayo de Mario Humberto Ruz «La familia divina. Imaginario hagiográfico en el mundo maya» (2006).

11 Las etnografías sobre mayas peninsulares que han abordado los espacios internos de las comunidades se refieren al «Centro» como el lugar donde residen los descendientes de los españoles (Quintal et al. 2003a) o «el asiento histórico de la cultura europea» (Thompson 1974: 38). Aunque en la plaza y algunas avenidas principales de Nunkiní todavía sobreviven algunas de las antiguas casas de mampostería de época colonial, la mayoría de sus residentes actuales poseen apellidos indígenas. Asimismo, en el centro se escucha cotidianamente hablar maya a hombres y mujeres, jóvenes y ancianos; los vecinos de todos los barrios acuden a sentarse en las bancas de la plaza a conversar durante las tardes. En Nunkiní no acontece lo que en otras poblaciones peninsulares, en las que el Centro es un espacio que ha sufrido un proceso progresivo de urbanización y desmayanización, en el que hasta las comisarías ejidales, órganos de representación de los campesinos, se ha visto 
Pero como cabría suponer en un listado como el que acabamos de ofrecer, tan profuso en barrios y capillas, la historia y vigencia que presentan cada uno de estos espacios intracomunitarios es, a día de hoy, dispareja y muy diversa entre sí. Lo anterior nos obligará a desechar las generalizaciones de conjunto en torno al surgimiento, funcionamiento y papel que desempeñan los barrios en Nunkiní. Por ello, a continuación, pretendo ceñirme exclusivamente a un par de aspectos muy concretos. $\mathrm{Mi}$ objetivo será el de ofrecer un primer y somero acercamiento al imaginario existente en torno a los dos rumbos históricos de la población, el norte y el sur, y referir algunos de los mecanismo que, desde la tradición oral y la práctica religiosa, ponen en práctica quienes los habitan para mostrar y reforzar su sentido de pertenencia a ellos. Los datos y las reflexiones que a continuación ofrezco para tratar de ilustrar esta pequeña parcela de la realidad cotidiana de Nunkiní forman parte del proyecto «Las capillas y sus santos: identidades barriales en una comunidad maya de Campeche», que actualmente me encuentro desarrollando, y el cual se encuentra todavía en fase inicial. Debido a ello, lo que se expone a continuación tiene mucho de etnografía en estado inicial y de reflexiones incipientes.

\section{Primero fueron el norte y el sur}

A tenor de los numerosos testimonios recopilados durante mis estancias de campo en Nunkiní, hasta hace poco más de cuatro o cinco décadas no existían más que tres subdivisiones internas de la población reconocidas por el común de los vecinos. La primera de ellas correspondía al Centro, y las otras dos al norte y al sur de la comunidad, respectivamente representados por los actuales barrios de San Román y el Gato Negro, mismos que por aquel entonces únicamente eran considerados «rumbos» de la población y no barrios, como sucede en el presente. Los espacios donde se yerguen actualmente los barrios y las capillas de san Martín, san Isidro, la Guadalupe o el Divino Niño que les dan nombre, apenas sí estaban habitados y, según los informantes, «todo era puro monte por allá». No fue hasta que comenzaron a llegar familias a poblar esos lugares alejados del centro, y que éstas comenzaron a organizarse para rendir culto a determinadas cruces familiares o a imágenes de santos ${ }^{12}$, que se inició la construcción por parte de los propios vecinos de las capillas que terminarían por dar nombre a los barrios que conforman a día de hoy la población.

Por su parte, la añeja división que existía entre el rumbo norte y el rumbo sur, y por ende entre los dos segmentos territoriales que se diferencian (y hasta oponían)

desplazadas de la plaza central hacia los barrios para dejar espacios a los comercios de la élite no indígena (Quintal et al. 2003b).

12 Los santos patrones de los barrios que presiden las capillas son de dos clases. En las capillas más antiguas, como San Francisco, San Román o San Marcelino, los santos son grandes y antiguas cruces de madera pintadas que reciben el nombre del santo correspondiente, mismo que aparece escrito en la base de la cruz. Por el contrario, en las capillas de reciente creación, como San Isidro, la Guadalupe o el Divino Niño, los santos están representados por sus imágenes «oficiales». Éstas fueron adquiridas en tiendas de artículos religiosos de Mérida o Campeche por las familias impulsoras del culto (caso de San Martín o la Guadalupe), o bien fueron regaladas a la capilla por algún sacerdote que estuvo de paso por la población (caso del Divino Niño o de San Isidro). 
entre sí por los propios vecinos desde que hay memoria, encontraba su frontera en una línea este-oeste que seccionaba en dos mitades a la población. Hasta hace 50 años, dicha línea divisoria estaba formada por los rieles por donde circulaban las «plataformas» que, tiradas por caballos, servían para comunicar Nunkiní y poblaciones aledañas con la cabecera municipal, Calkiní. En la actualidad, sobre los rieles se encuentra la carretera principal que parte por la mitad Nunkiní, y que en dirección oriente lleva a Calkiní y hacia el poniente conduce al vecino poblado de Santa Cruz. Con estas palabras rememoraba un vecino de 75 años aquellos tiempos:

«de antes no había tantos barrios como ves ahorita. No había más de dos. Era del lado norte y del sur... así se conocían: el rumbo del sur y del norte. Lo dividía la calle de la carretera... pero a un principio eran rieles para plataformas, y a un lado era el Gato y al otro San Román».

En ese tiempo pretérito, antes de que ninguna capilla prestara su nombre a los espacios habitados de la comunidad, la forma que empleaban los antiguos vecinos de Nunkiní para nombrar y clasificar los distintos lugares de su comunidad se encontraba íntimamente ligada a la existencia de pozos públicos y a los nombres que éstos recibían en función de alguna característica particular que los identificaba ${ }^{13}$. Así, por poner solo algunos ejemplos, el lugar donde actualmente se levanta la capilla de san Francisco era conocido popularmente como cruz-chén ${ }^{14}$, pues junto al pozo había un oratorio de piedra con una gran cruz de madera en su interior. Por su parte, cháaltúnchén ${ }^{15}$ era el nombre que recibía la explanada donde actualmente se localiza la capilla de San José, en función de la gran laja de piedra lisa y plana que se utilizó para construir la boca del pozo que en ella había. También en el sur, pero mucho más hacia el oriente, en lo que hoy es parte del barrio del Divino Niño, se hallaba otro rumbo que se conocía como choch 'háchén ${ }^{16}$, gracias a la existencia de un pozo cuya agua, al beberla, dejaba un fuerte y persistente sabor salado en la boca.

Pero no sólo de pozos se servían los nunkinienses para clasificar y apropiarse de los espacios internos de su comunidad. El rumbo del actual barrio de San Martín era designado bajo el nombre de oxpexiú, literalmente «tres hierbas». Cuentan los informantes que este nombre deriva del hecho de que en ese rumbo residían los miembros de una familia muy popular en toda la región, porque sus miembros varones aseguraban conocer el secreto de varias hierbas que les servían para preparar medicinas. A estos remedios recurrían muchas personas, tanto de dentro como de fuera de la población, en busca de un remedio definitivo contra sus padecimientos.

13 En las poblaciones mayas peninsulares los pozos agua han tenido una gran importancia en función de la escasez de agua que existe. La necesidad de compartirlos, amén de la necesidad de establecer relaciones de reciprocidad entre unidades domésticas emparentadas, ha servido para explicar la residencia compartida de los grupos de familias extensas (Quintal et al. 2003a).

14 Literalmente «cruz-pozo». Este pozo se ha mantenido intacto en su lugar original, hoy convertido en la plaza donde se levanta la capilla de san Francisco. En recuerdo a su antiguo nombre que se derivaba del hecho de tener dos maderas cruzadas sobre su boca, el pozo cuenta hoy con una cruz de hierro coronando el arco de herrería donde se asienta la polea que se utiliza para extraer las cubetas de agua de su interior.

15 Cháaltún es una piedra plana y lisa de gran extensión, típicas del área peninsular cuyo suelo está conformado en sí mismo por una gran laja de piedra caliza.

16 Literalmente se puede traducir como «pozo de agua salada». 
Las categorías espaciales que hemos mencionado cumplían con una doble función utilitaria: por un lado permitían a los vecinos de Nunkiní apropiarse de los distintos espacios que conformaban el paisaje doméstico y cotidiano de su comunidad y, por otro, les ayudaban a ubicarse dentro de éste. El extendido uso que debieron de tener todos estos topónimos en épocas pretéritas se vislumbra todavía en la actualidad a través del empleo cotidiano que hacen actualmente de ellos las personas que superan el medio siglo de edad, quienes los alternan caprichosamente con los nombres de los barrios y capillas actuales.

\section{3. «La época de la violencia»: luchas entre el norte y el sur}

Pero si hay algo que ha quedado grabado a sangre y fuego en la tradición oral de Nunkiní en relación a la historia de sus barrios, es el violento antagonismo que existió en el pasado entre el norte y el sur de la población, o lo que es lo mismo, entre los vecinos de los actuales barrios de San Román y el Gato Negro. Al respecto, en lo que no se ponen de acuerdo las narraciones contemporáneas es sobre la época precisa en la que comenzó dicho conflicto, pues mientras algunos informantes lo retrotraen hasta fechas anteriores al arribo de los españoles al pueblo, otros no consideran que tenga mucho más de un siglo. Sea como fuere, el hecho es que el conjunto de «historias» que tratan de explicar los orígenes del conflicto se ubican dentro de un marco cronológico mítico que resulta imposible fijar con exactitud ${ }^{17}$.

$\mathrm{Al}$ respecto, una versión muy extendida es aquella que asegura que los arranques de esta tradicional enemistad entre los moradores de San Román y los del Gato Negro se encuentran en el hecho de que Nunkiní fue poblado, desde tiempos muy remotos, por dos «razas» diferentes: una era autóctona de estas tierras y la otra vino del exterior para asentarse definitivamente en el pueblo. Don Alvino Collí, un natural de 75 años, explica así lo sucedido en esa época pretérita:

«dicen que gente de otra raza, los aztecas dicen que eran, vinieron aquí desde allá, de muy lejos así. Muchos iban a buscar esos caracoles grandes; del mar los agarraban y no más que eso comían. Así fue que llegaron a vivir acá. Buscaron donde quedarse por el sur [de Nunkiní] ${ }^{18}$, porque en el norte ya estaban viviendo los antiguos de esta tierra... $\mathrm{y}$ allí se quedaron».

Por su parte, Don Camacho Chí, de 72 años, afirma que, a pesar de no conocer bien la historia su padre le contaba que: «los del Gato [en el sur de la población] vinieron de México y los de San Román eran los mayas que estaban por acá»». Siguiendo esta misma línea argumentativa, otros informantes con los que he podido hablar

17 Siguiendo a Gutiérrez Estévez (2001), este tipo de relatos sobre el pasado convulso de la población entraría dentro del género de conversación que el autor denomina «historias», que son aquellas narraciones que remiten a un pasado que los narradores inscriben como acontecimientos memorables del pasado local. Dentro de este género se pueden incluir desde milagros de los santos patrones hasta incidentes bélicos o catástrofes agrícolas. Sobre la variedad de géneros narrativos mayas peninsulares puede consultarse también el trabajo de Allan F. Burns (1995).

18 Los textos que aparecen entre corchetes en el interior de las citas de los informantes son añadido del autor con fines meramente aclaratorios. 
identifican a los que llegaron a poblar el sur de Nunkiní como «gentes que venían de fuera»; refiriéndose a ellos, indistintamente, como «toltecas», «zapotecos», «chiapanecos» o «gentes del centro del país».

Este conjunto de relatos coinciden en insistir que los dos grupos, el foráneo y el autóctono, evitaron casarse entre sí y vivieron siempre separados uno del otro durante siglos: «era raro que salieran de su barrio: dicen que entre ellos se casaban, en ese rumbo iban a sus tierras y allí tenían sus pozos, no cruzaban para el otro rumbo», apuntilla don Cornelio ${ }^{19}$. La prueba irrefutable a la que aluden siempre los nunkinienses cuando rememoran el periodo en el que se forjaron las divisiones internas de la comunidad es la existencia, visible hasta la fecha, de dos panteones: uno en el norte y otro en sur. $\mathrm{Y}$ es que, a decir de otro informante, «los que llegaron acá se fueron dividiendo. No quisieron juntarse con la gente que estaba por acá viviendo de antes. Se dividió para siempre la cosa, por eso desde ese tiempo están los dos cementerios en Nunkiní». «Ni difuntos pueden andar juntos, por eso hay dos panteones: el del sur y al norte», añade al respecto don Elías Chí Canul.

El encuentro entre estas dos poblaciones, o «razas», de orígenes tan dispares se tradujo, según las opiniones expresadas por algunos vecinos, en la existencia hasta hace pocos años de variaciones físicas notables entre las personas que habitaban en el norte y el sur de Nunkiní. Como doña Olga, una vecina que reside en la plaza, apunta:

«los del Gato eran altos y mucho más negros, los del sur no, son más chaparros y su piel menos oscura que los otros... de hace tiempo así era, hasta hoy los nietos son más chaparritos».

Pero además de las versiones que acabo de referir, la gran mayoría de los vecinos de Nunkiní remiten a episodios históricos más recientes y mucho más traumáticos para explicar la división y los enfrentamientos que se dieron, hasta hace muy pocos años, entre los dos rumbos de la población. Para ello, la tradición oral local nos sitúa en las que denomina «época de la esclavitud», vinculada a las haciendas henequeneras, y la «época de la violencia», las cuales se sitúan a principios del siglo pasado, fijando como eje cronológico identificable la visita que a Nunkiní hizo Felipe Carri1lo Puerto ${ }^{20}$. La memoria que todavía pervive sobre este periodo tan convulso de la historia local es bastante heterogénea y no está exenta de opiniones contrapuestas y posturas irreconciliables, pues muchos de los progenitores y abuelos de los actuales narradores vivieron y sufrieron en primera persona los enfrentamientos y las persecuciones, transmitiendo a sus descendientes una visión particular y personalista de los acontecimientos que se dieron en aquel tiempo.

19 Esta endogamia entre las mitades que conformaban la comunidad no es extraña en el área cultural mesoamericana. Al respecto Saúl Millán (2003: 18-19) ha apuntado que «las unidades territoriales, regulan las preferencias matrimoniales y prefiguran una tendencia estadística a la endogamia que se expresa en la organización territorial del espacio comunitario», lo que se entrevé actualmente en numerosos barrios, secciones o mitades de poblaciones indígenas mesoamericanas. A tenor de estos hechos, el autor supone que «las sociedades precolombinas contaban con reglas de matrimonio mucho más explícitas que las que vemos hoy, y que su funcionamiento no era ajeno a un conjunto de unidades endógamas de carácter territorial».

20 Se trata de las pugnas, muchas veces violentas, que se vivieron entre los partidarios del partido liberal y el partido socialista (del cual Carrillo Puerto fue líder y llegó a alcanzar la gobernación del estado de Yucatán) en la segunda década del siglo XX en toda la península de Yucatán en el contexto postrevolucionario. 
Así, la naturaleza y las causas del antagonismo que se dio entre el norte y el sur de Nunkiní son variables y se explican, a grandes rasgos, sobre la base de dos modelos de narraciones bien diferenciados. Los relatos que incluyo en el primer grupo recurren a un doble componente, de tipo étnico y de clase, para justificar estas diferencias y las posteriores luchas que se vivieron en la población. Según este primer modelo narrativo, en el sur era donde residían todos los «dzules», quienes portaban apellidos de origen hispano (Suárez, Pinto, Ávila, Flores, Gamboa). A este grupo se refieren los testimonios como los «ricos del pueblo», los «caciques», o quienes desde siempre habían detentado el poder político y económico en Nunkiní. En palabras de un informante:

«de antes los del sur eran los que tenían todas las tiendas, el ganado, todo; eran los que gobernaban, siempre las mismas personas que se cambiaban en los puestos, que secretario, que tesorero, que Presidente. No más ellos ocupaban los cargos en el Palacio»;

lo que el mismo informante explica aduciendo que:

«eran los que tenían lana para pagar los estudios en Calkiní, porque para el gobierno había que hablar bien el castellano, escribir rápido y expresarse bien».

Por su parte, según estas mismas versiones, en el norte de Nunkiní residía mayoritariamente «la gente pobre». Ésta se identifica siempre en las narraciones de la actualidad con la imagen tradicional del campesino milpero, los peones asalariados que trabajaban en las haciendas colindantes, y, eso sí, se destaca que «eran puros mayeros ${ }^{21}$; los cuales estaban sometidos a los gobiernos arbitrarios de los dzules del sur. Un anciano de 77 años, vecino de San Román, me explicaba así las diferencias entre los habitantes de uno y otro rumbo de la población:

«por acá [San Román] eran las gentes pobres, así. Tienen que llevar su pantalón poco por debajo de la rodilla y calzan puro tabixaná. Los ricos estaban por allá [Gato Negro], del otro lado del riel para el plataforma: esos puro pantalón hasta el suelo llevan y sus zapatos son cerrados»».

Así, siempre según las narraciones pertenecientes al que he denominado primer modelo, las diferencias entre el norte y el sur se tradujeron pronto en una pugna que se fue volviendo cada vez más enconada y violenta. De esa forma los campesinos pobres residentes en la mitad norte de Nunkiní se cansaron de sufrir las arbitrariedades de los dzules del sur en el poder. Fue así como, a raíz de una visita a Nunkiní de Felipe Carrillo Puerto, se unieron para luchar en contra de ellos e intentar arrebatarles sus privilegios.

Esta visión un tanto maniquea e idealizada, que muestra la lucha de norte contra sur como un enfrentamiento entre pobres y ricos e indígenas contra $d z u l e s$, se ve rebatida por un segundo grupo de relatos también muy presentes en la tradición oral. Según estas versiones, en lugar de una lucha en pos de la justicia y la libertad, lo que detonó la violencia en Nunkiní fue una pugna entre familias poderosas del norte y el sur, las cuales buscaban hacerse con el control político y económico local. Para la lucha en favor de sus propios intereses, ambas familias recurrieron a contratar cuadri-

21 «Mayero» es una expresión habitual que se utiliza en toda la península de Yucatán para referirse a las personas cuya lengua materna es el maya. 
llas de hombres, a los cuales invitaban a beber y después embaucaban con «palabras bonitos» para ir al barrio contrario y cometer actos de violencia en contra de los que allí residían.

En lo que sí se muestran de acuerdo casi todas las narraciones es en señalar la llegada de Felipe Carrillo Puerto a Nunkiní como el detonante de lo que se ha dado en llamar «la época de la violencia» $»^{22}$. Fue tras uno de sus discursos incendiarios en contra de los privilegios de los ricos caciques de apellido hispano, pronunciado a la sombra de un gran ciruelo centenario situado en el costado sur de la explanada de San Román, cuando se fundó en ese barrio una de las muchas ligas de resistencia socialista que se popularizaron por toda la Península durante los años veinte. Así, quienes formaron la Liga de Resistencia Socialista de San Román recibieron rápidamente el apelativo de «los rojistas», mientras que sus adversarios del sur se organizaron en otro grupo que pasó a denominarse «los verdistas». Para distinguirse, los miembros de uno y otro bando portaban en sus camisas cintas de color verde o rojo, según la adscripción de cada quien. Cuentan los informantes que si por casualidad se encontraban los integrantes de ambos bandos por las calles «había bronca seguro» y «rápido comenzaban los putazos». Así las cosas, ambos bandos intercambiaron agresiones durante un tiempo prolongado, resultado de las cuales numerosas viviendas fueron incendiadas tanto en el norte como en el sur de Nunkiní, sin que éstas necesariamente perteneciesen a familias que estuvieran directamente implicadas con alguno de los grupos enfrentados, lo que provocó gran temor y preocupación entre toda la población.

Como parte de toda esa tensión que se respiraba en Nunkiní durante ese tiempo, muchos informantes recuerdan cómo resultaba imposible cruzar de un barrio al otro sin ser agredido o detenido por integrantes de cualquiera de los dos bandos en conflicto, pues el mero hecho de residir en el otro barrio los convertía en enemigos. Ante esta situación, los vecinos procuraban no abandonar sus barrios para nada. Con enojo recuerda aquellos días don José Hass, un campesino de casi 80 años:

«en ese tiempo estaba jodida la cosa con la política: cuando cruza uno de allá para este lado lo van a romper la madre. Cuando entra uno para el otro barrio es peligroso, si te ven te van a sacar con piedras, con golpes, ahí que te llevan al bote, estaba muy mal esa época. La gente está divisionada (sic), no pueden verse por el pleito que traían los verdistas y los chakistas».

Tal era el grado de incertidumbre y pánico que sufrían los vecinos de ambos barrios, atrapados entre la violencia desatada por los dos bandos en conflicto, que muchas familias enteras tanto en el norte como en el sur optaban por abandonar sus casas cuando caían las noches para buscar refugio en los montes cercanos a la población. Con esta medida, los jefes de los grupos domésticos trataban de evitar encontrarse en sus domicilios con sus esposas e hijos durmiendo, cuando los grupos de choque del otro barrio llegasen a quemar casas por el rumbo donde ellos vivían. Retomando lo que le contaba su madre, un vecino de San Román recuerda así este periodo:

\footnotetext{
22 No obstante, muestra del carácter mítico que han alcanzado ya estos sucedidos en Nunkiní, algunos de los testimonios recopilados entre los vecinos de Nunkiní ubican esta llamada «época de la violencia» en los tiempos de la Revolución e, incluso, hay quienes mencionaron los tiempos del cura Hidalgo para ubicar los sucedidos.
} 
«Esas gentes que queman las casas...mi pobre madre estaba como de 15 años. Y mi abuelo los agarra a todos: a su esposa, a sus hijos y lo llevan al monte. Allá pasa las noches, en el monte...Aparece un pozo, aktúnes le dicen, allá se meten todos para que no haiga ruido. Mare está triste la cosa. Porque esa gente no te va a decir que van a quemar tú casa. Están andando locos, no lo sabe uno donde van a meter candela a la casa de guano y rápido quema todo».

Una muestra más del nivel que alcanzó esta rivalidad entre barrios la encontramos en el hecho de que, hasta muchos años después de acabados los enfrentamientos, no se permitió que las mujeres se casaran con varones que no fueran de su misma colonia. De hecho, muchas personas recuerdan todavía como las chicas solteras, al salir de sus casas, debían llevar colgados de sus hipiles un lazo de color verde o rojo, dependiendo de su lugar de residencia, para de esa forma mostrar públicamente el barrio al que pertenecían, y disuadir a los posibles pretendientes despistados.

La violencia entre «rojistas» y «verdistas» culminó con el asesinato a machetazos de un grupo de personas que habían sido encerradas en la cárcel de Nunkiní, que por aquel entonces se encontraba en el interior del actual Palacio Municipal. El número de muertos oscila, según las diferentes versiones recopiladas, entre siete y quince personas. Donde no hay discrepancias es en el hecho de que los finados pertenecían en su mayoría a la familia de los Suárez, una de las más ricas y poderosas que había en Nunkiní por aquellos tiempos. Algunos informantes justifican hoy en día los asesinatos aduciendo que, durante los años en que los Suárez ocuparon el poder, se detenía y encerraba arbitrariamente a los campesinos con el único objetivo de, en las noches, acercarse a sus viviendas y obligar a sus mujeres a mantener relaciones sexuales con ellos a cambio de poner en libertad a sus cónyuges. Así refiere aquellos sucesos don Amadeo Hass, un campesino de 75 años al que su padre narró que:

«Se llevan mal la gente porque en ese tiempo el presidente oye que uno que está borracho y le dice al comandante que lo metan al bote y ijalá, vas pa dentro! Y el otro se va con su esposa, llama a su puerta y dice: abra señora, vamos a platicar contigo. Esto y esto. No más cuando yo salgo ordeno al comandante que saca tu marido».

Otra versión relativa a estos los mismos agravios, pero ofrecida por otro vecino de 78 años residente en el norte de la población, se muestra aún más rica en detalles y en opiniones personales respecto a como esos agravios fueron los detonantes y sirvieron para justificar (todavía en la actualidad) la matanza que acaeció en Nunkiní:

«Ese tiempo, es que los Suárez son autoridades allá [en el Palacio]. Aunque tú no hiciste nada, así, ellos te chingan, te dan tu cárcel y después van con tu esposa. Eso no está bien. Mare, pero cuando les cayeron todos así. Está encabronada la gente. Creo que como 12 o 15 los metieron en el bote a ellos y después entraron la gente y machetearon en la cárcel. Ya está, mataron esos cabrones. Odian a esos cabrones... porque, si después que te meten allá [en la cárcel] te chingan en tu casa, ¿Qué vas a hacer? Hicieron enojar, por eso los mataron».

Por último, resulta interesante mencionar una última versión sobre estos hechos. Ésta procede de la descendiente de una de las pocas familias que quedan en el centro de Nunkiní con apellidos hispanos. Para esta mujer de 70 años, que dejaré en el anonimato por razones obvias, los motivos de la matanza fueron bien distintos a los 
señalados hasta aquí. Asegura esta informante que, aunque los Suárez fueron mayoría entre los asesinados, en la matanza también perecieron miembros de las familias Gamboa y Pinto. Para ella, como para otros portadores de apellidos hispanos con los que he podido hablar, la matanza estuvo instrumentalizada por un grupo de personas que sentían «envidia» de los Suárez, a quienes ella describe como una familia de prósperos comerciantes de Nunkiní. Además, mucha gente les debía dinero, porque «esos Suárez le daban fiado a la gente que no tiene dinero cuando iban a su tienda. Dicen: no te preocupes, ya me lo das cuando tengas». Un tercer factor que desencadeno la matanza estuvo relacionado, siempre según la versión de esta informante, con que

«parece que [los asesinados] eran muy mujeriegos y se llevaban a muchas muchachas de las familias campesinas, por eso los machetearon. Primero quemaron las casas donde vivían esos señores, acá por el Gato, y luego los encerraron en el Palacio, allá los mataron a todos».

Lo que sucedió a posteriori con los cuerpos y las ánimas de los asesinados durante esa jornada varía muy poco de unas versiones a otras. En algunos relatos, los autores de la matanza cortaron los órganos genitales de los cuerpos ya sin vida y los clavaron en las puertas de las que habían sido sus tiendas y viviendas. Este hecho deja entrever la naturaleza punitiva que tuvo la matanza, con la cual se quiso vengar las violentas y abusivas prácticas sexuales que gustaban practicar los finados en el pueblo. Por el contrario, otras versiones rebajan algunos grados el nivel de dramatismo del suceso, asegurando que lo que se cortaron de los cadáveres fueron «únicamente» las orejas, mismas que fueron clavadas en los muros de la única cantina que había en Nunkiní por aquel entonces. Sobre las ánimas de los finados y su venganza, los castigos divinos que sufrieron los asesinos y el papel que tuvo San Diego hablaré en otra ocasión.

Donde las narraciones no dejan lugar para las dudas es en el hecho de que la matanza fue orquestada y perpetrada por el grupo de los «rojistas», aunque en todos los casos los narradores aseguran desconocer los nombres de los autores materiales de la escabechina. Este desconocimiento se debe, argumentan los informantes, al hecho de que los verdugos iban con sus cuerpos cubiertos con costales de soskil ${ }^{23}$ de pies a cabeza. A su vez, este sucedido violento concluyó con el denominado «periodo de la violencia», pues desencadenó la precipitada salida de Nunkiní de muchas familias de dzules, las cuales se asentaron en Mérida, Campeche o Calkiní. De igual forma, la llegada del ejército federal para poner fin a la violencia y buscar y castigar a los autores de la matanza, provocó que muchos de los «rojistas» tuvieran que abandonar la población para evitar ser encarcelados.

\section{Viejos santos, nuevas capillas: el surgimiento de los barrios}

Hasta aquí hemos podido constatar los motivos históricos e imaginarios, que la tradición oral de Nunkiní evoca para explicar la profunda fragmentación que existió en el seno de la población durante buena parte de su historia. Como apuntamos al principio,

23 El soskil o sisal son las fibras que se extraen de la planta del henequén ( $k i$, en maya) o agave fourcroides, muy utilizadas para fabricar cuerdas y sacos. 


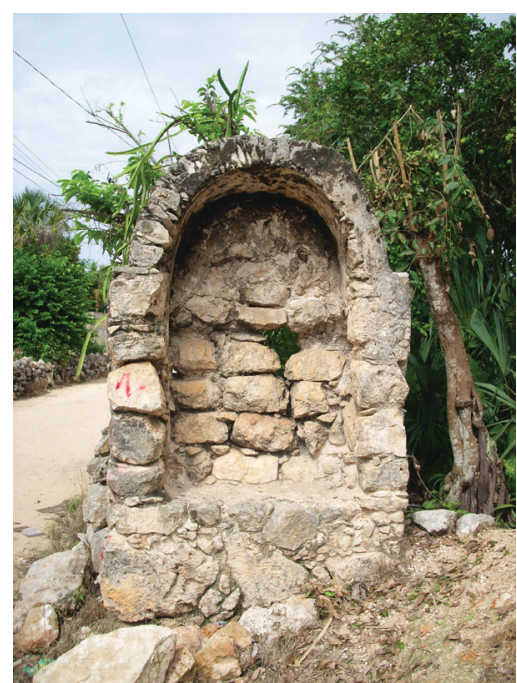

Figura 4: Uno de los varios «olatorios» que todavía sobreviven en Nunkiní. Antiguamente estas construcciones albergaban en su interior a los santos familiares.

más que dos barrios, lo que había en Nunkiní eran dos rumbos antagónicos, endógamos y enfrentados; cuyos habitantes apenas se relacionaron en sus quehaceres cotidianos. Los vecinos de las dos partes recuerdan que «Era raro que la gente saliera de su barrio, allá por su rumbo iban a la escuela, al molino, a buscar agua al pozo y a trabajar la milpa». De la misma forma, y como ya señalé, se trataba de unidades territoriales endógamas, cuyos integrantes impedían que se pudieran llevar a cabo matrimonios entre vecinos que pertenecieran a los dos rumbos diferenciados de la población. Si bien la fiesta patronal en honor al santo servía para reunir al conjunto de la población en el centro y rendir culto comunitario al santo patrono de la localidad, lo cierto es que los primeros gre$\operatorname{mios}^{24}$ que se fundaron en Nunkiní estaban conformados íntegramente por vecinos del mismo barrio al que pertenecía el patrón y fundador de la sociedad y su familia. En la actualidad pareciera que esta rivalidad norte-sur se haya ido depositando en los cajones más profundos de la memoria. Sin embargo, basta con escuchar algunas de las apasionadas narraciones que de la época de la violencia hacen los ancianos en la actualidad, para comprobar que los cajones donde se depositan esos recuerdos permanecen entreabiertos.

En épocas mucho más recientes, la creación de distintos grupos de devoción en torno a diversas cruces y santos que en origen poseían carácter familiar y que actualmente han alcanzado un estatus territorial intracomunitario, ha venido a resquebrajar la histórica dicotomía que existía entre el norte y el sur de la población. Por mencionar sólo el ejemplo más antiguo, hace más o menos 60 años se levantó en el noroeste de Nunkiní la capilla de San Francisco, después de que varios integrantes de la familia Balam que residían por aquel rumbo decidieran romper con el duopolio que mantenían los barrios de San Román y San Marcelino. Para ello, los miembros de esta familia decidieron recurrir y conjuntar a los miembros de otros grupos domésticos asentados por su mismo rumbo. A sus vecinos les expusieron sus deseos de construir una capilla de piedra sobre un terreno descampado que había en torno al pozo comunitario que existía en ese segmento de la población (cruz-chén). El objetivo era llevar, resguardar y celebrar en su interior las cruces-santo que algunas familias aledañas habían heredado de sus antepasados, muchas de las cuales se conservaban en los antiguos y maltrechos «olatorios» ${ }^{25}$ que tenían dentro de sus solares (Figura 4).

24 Los gremios es el nombre con que se conocen en la Península a las organizaciones laicas de devotos, mayoritariamente de carácter familiar, que se encargan de solemnizar cada uno de los días en que transcurren los festejos que las poblaciones dedican a sus santos patrones.

25 Los «olatorios» son antiguas y sencillas construcciones de piedra abovedadas, a modo de nichos, que se levantaban en el interior de los patios domésticos para resguardar a los santos familiares. Aunque la mayoría 
Figura 5: Los santos-cruz de la capilla de san Francisco; en el centro, la imagen del santo recientemente adquirida.

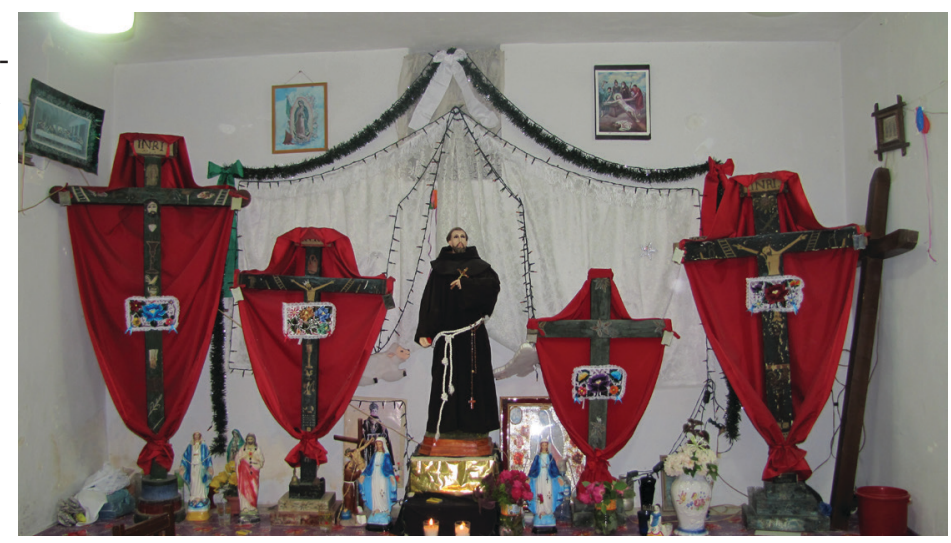

Con tal fin, ofrecieron a sus vecinos participar junto a ellos en las tareas de construcción de la capilla $\mathrm{y}$, posteriormente, que entraran a formar parte de la «sociedad» que se encargaría de organizar y festejar la novena al santo que daría su nombre al nuevo barrio durante los días de su fiesta.

Una vez que los hermanos Balam hubieron conseguido las cuatro cruces (o santos) con que actualmente cuenta la capilla de san Francisco, la primera de ellas con el nombre del mencionado santo inscrito en su base, compraron con su propio dinero una parte de los terrenos donde actualmente se levanta el edificio y comenzaron su construcción. Éste se ubicó en el extremo norte de la explanada que hoy constituye el centro neurálgico del barrio y posee forma rectangular, con una extensión de siete metros de largo por cinco de ancho. En sus formas recuerda a la iglesia de la localidad, pues su fachada principal está coronada por una espadaña con espacio para cuatro campanas, en la cual sólo hay una, y un par de almenas decorativas en los extremos. Para los trabajos de construcción contaron con el apoyo de algunos vecinos quienes, en la medida de sus posibilidades, colaboraron en la construcción de la capilla con dinero y, sobre todo, aportando su propio tiempo y fuerza de trabajo (Figura 5).

De forma similar, varias de las antiguas cruces de madera familiares que había repartidas por todos los rumbos de Nunkiní vinieron a abandonar sus tradicionales dominios en el interior de los espacios domésticos (bien sobre los altares de las viviendas, bien en los «olatorios» que había en los solares), para extender sus «territorios de gracia» ${ }^{26}$ hacia el exterior. De esta forma, los santos hasta entonces familiares vinieron a sacralizar y prestar sus propios nombres a varios barrios que hasta ese momento no existían como tales. En efecto, siguiendo el ejemplo de San Francisco, son numerosos los informantes que aseguran que hasta que no se hubo levantado la actual capilla, se llevaron los santos a su interior y se comenzó a celebrar en su honor el complejo ritual y ceremonial de las novenas, con el cual se ha venido festejando a

de ellos han desaparecido hoy en día, todavía se pueden ver los restos de algunos derruidos junto a las albarradas que separan los solares de la calle.

${ }_{26}$ El «territorio de gracia» del santo es aquel sobre el cual los hombres sienten su protección e influencia, y, por tanto, es el territorio sobre el cual éstos construyen una lealtad a esa imagen (Christian 1978). En este caso, el territorio de gracia de los santos epónimos de cada barrio se establece simbólicamente a través de su procesión anual el día de su fiesta, cuando la imagen recorre los linderos que delimitan el barrio. 
las cruces epónimas de las colonias hasta la fecha, el actual barrio de San Francisco no dejó de ser «el rumbo de cruz-chén» para adquirir su actual estatus. De hecho, la opinión más generalizada entre los vecinos es que, para que un barrio se conforme y pase a denominarse como tal, «no más la gente del rumbo se une y comienzan a hacer sus bailes, sus corridas, hacen la coperacha para la iglesia, para su fiesta...no más así es que ya se formó el barrio».

Siguiendo con el caso del barrio de San Francisco que nos ocupa, una vez que hubieron finalizado la construcción de su capilla, y en vista del gran número de ofrecimientos que recibieron por parte de otras familias que residían por ese mismo rumbo para poder tomar partido y colaborar en los preparativos de las celebraciones que se dedicarían al santo, los integrantes de la familia Balam no tardaron en organizar la «sociedad» de San Francisco. La tarea fundamental de esta agrupación de vecinos sería la de financiar, organizar y ejecutar los diferentes eventos, tanto religiosos (rezos nocturnos, una misa y la procesión) como lúdicos y «profanos» (bailes, repartición de comida y hasta corridas de toros $)^{27}$, que conformarían el programa de los nueve días de la fiesta (la novena) que se realizan en honor al santo del barrio. Todos estos eventos conmemorativos transcurren en todo momento dentro de la capilla (los de carácter sagrado) o en la explanada donde ésta se ubica (los profanos), reforzando así la centralidad de la figura del santo en ellos y el carácter esencialmente barrial de los festejos. Lo anterior permite crear un sentimiento de especificidad propio entre los residentes del barrio que organiza la fiesta, a la cual acuden los vecinos de otros barrios de la localidad. Prueba de todo ello es que en la memoria colectiva de los vecinos mayores de Nunkiní sobreviven los recuerdos de aquellos primeros y dorados años de la fiesta de San Francisco en los que, en la misma plaza del barrio, la «sociedad» del santo ofrecía cada año «a todos los que gustaban acompañarnos» desde nueve días antes del 4 de octubre, «día del aniversario del santo», tardeadas con música en vivo, bailes populares, venta de cerveza con regalo de botana, máatan $^{28}$ de algún guiso de fiesta $\mathrm{y}$, en sus mejores años, hasta corridas de toros en un ruedo que se levantaba frente a la capilla (Figura 6).

Actualmente, con los patrones originarios de la capilla y de la sociedad de san Francisco ya fallecidos, quienes asumían la mayor parte de los gastos derivados de la celebración (como sigue pasando en la actualidad en otras capillas), las mentadas celebraciones de carácter profano que hace varias décadas hicieron tan populares las fiestas de este barrio se han visto reducidas a su mínima expresión. Hace apenas unas cuantas semanas, uno de los hijos del fundador de la sociedad de san Francisco me

27 Esta distinción entre eventos religiosos y profanos en el marco de los festejos que se le dedican a los santos patrones en la península es de carácter emic. Hasta los carteles publicitarios que empapelan postes y muros de los pueblos para anunciar las Ferias de las poblaciones publicitan los diferentes eventos que tendrán lugar durante sus transcurso en función de su carácter «sagrado» (novenas, gremios, misa, procesión) o «profano» (vaquería, corridas, bailes). Sin embargo, resulta obvio que esta división no es tajante, pues la figura del santo festejado es la que dota de sentido a toda la celebración y la sacralidad es la tónica predominante durante la fiesta (Ruz 2007: 301).

28 Máatan significa, literalmente, «regalar». Así se denomina a la acción repetida en todas las celebraciones religiosas (tanto las vinculadas con la tradición católica como indígena) de repartir comida entre todos los asistentes a la misma. Similar, pero con matices es el término t'oox, que significa «repartir, distribuir o dividir». 
comentaba con visible resignación que «si los vecinos apoyan en algo», quizá para este año puedan volver a realizarse alguno de los tradicionales eventos lúdicos que se fueron abandonando en los últimos años. Su idea es la de contratar a un «tecladista» que amenice con música en vivo la venta de cerveza que se realizará el último día de la novena, una vez haya concluido la misa que oficiará en la capilla del barrio el párroco local en honor al santo de este rumbo de la comunidad, la cual será costeada con dinero procedente de las arcas de la sociedad ${ }^{29}$.

Pero si la parte lúdica se ha visto bastante mermada en estos últimos años, las celebraciones estrictamente religiosas propias de la novena, así como la organización social que las sustenta, se han mantenido casi en su totalidad. Así, desde el 26 de septiembre y durante nueve noches consecutivas, en la capilla del barrio tiene lugar el rezo de dos rosarios por parte de una pareja de rezadoras profesionales, contratadas ex profeso para toda la novena. Un número variable de vecinos se darán

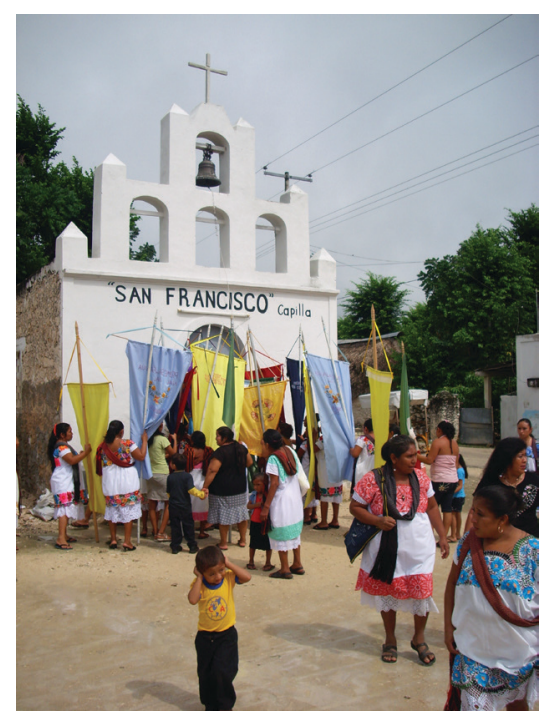

Figura 6: Las capillas de los barrios cobran especial relevancia durante las celebraciones religiosas. En la imagen un gremio deposita sus estandartes en la capilla de san Francisco durante el «novenario» del santo patrón. cita en torno a la capilla durante esas noches (el número de asistentes crece a medida que se acerca el final de la novena): los menos para seguir los rezos desde el interior, otros para conversar al fresco de la noche con parientes y vecinos, mientras que los más jóvenes se entretienen jugándose la calderilla que les han dado sus padres en la barra de lotería campechana que se instala a un costado de la capilla. Cuando el rezo está por concluir, varias integrantes de la sociedad de san Francisco darán inicio al tradicional $t^{\prime}$ oox, el cual consiste en la repartición de bebidas (como café, horchata, refresco o saká), algún platillo sencillo (como pasta roja o «sopa fría») y un postre dulce (del tipo arroz con leche, gelatina o galletas), entre todas las personas congregadas en la capilla y en la placita del barrio. Cada noche de rezo tiene su propio «encargado» o «encargados», dependiendo del número de socios que integran la sociedad cada año. Él o los encargados de la noche serán los responsables de pagar a las rezadoras por el rezo y de comprar, preparar y llevar hasta la capilla los alimentos que se vayan a repartir al finalizar los rezos. De esta forma los miembros de la sociedad de san Francisco reeditan, a nivel barrial, la tradicional reciprocidad y redistribución que acompaña las celebraciones de la religiosidad popular maya, en la que se involucran a partes iguales trabajo, dinero y alimentos (Figura 7).

29 Habitualmente, para ingresar como «socio» en cualquiera de las sociedades que se encargan de celebrar a los santos de los barrios es requisito realizar el pago anual de una pequeña cuota en metálico, misma que se destina a la caja de la sociedad bajo custodia del tesorero para poder hacer frente a los pagos derivados de los festejos. 


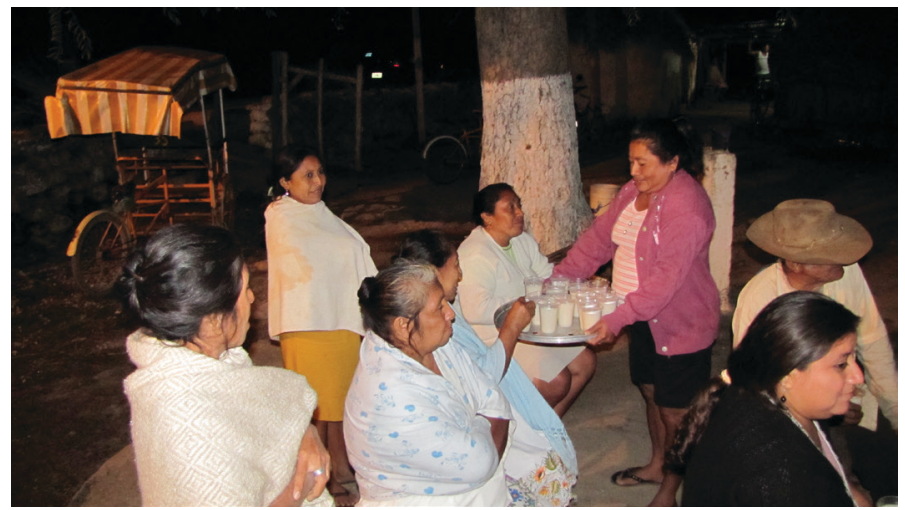

Figura 7: Al concluir cualquier rezo se procede con el tradicional máatan o repartición de comida y bebida entre todos los asistentes.

También a cargo de las arcas de la sociedad encargada de festejar a san Francisco, la cual se nutre exclusivamente de las cuotas de sus integrantes y de las donaciones ocasionales que realizan esporádicamente algunos vecinos que buscan cumplir así una promesa formulada al santo, quedará patrocinar la tradicional comida que compartirán todos los socios durante la última jornada de la fiesta. Esta comida colectiva, a la que únicamente tienen derecho asistir los socios, consistirá en un buen plato de boox ká o «relleno negro» ${ }^{30}$ para cada asistente, acompañado de abundantes tortillas de maíz hechas a mano y recién sacadas del fogón, y un número indeterminado de cervezas o refrescos bien helados. Antes del mencionado ágape, en la capilla del barrio se celebrará por la mañana una misa oficiada por el párroco de la localidad para, posteriormente, sacar en procesión por la plaza del barrio a la cruz que representa a san Francisco, la cual será llevada en diferentes turnos por varios socios, seguidos por numerosos vecinos y fieles.

Como es costumbre en casi todas las expresiones de la religiosidad indígena peninsular vinculadas con los santos patrones, diversión, apuestas, devoción, trabajo colectivo y consumo conjunto de alimentos ceremoniales se entremezclan sin distinción aparente compartiendo los mismos tiempos y espacios con la finalidad última de homenajear a los distintos númenes que señorean sobre la vida de las comunidades y sus habitantes. Al nivel barrial que ahora nos ha ocupado, todo este conjunto de experiencias festivas que son compartidas por los vecinos de un mismo segmento de la comunidad permiten a éstos construir, reforzar o reactualizar año con año un buen número de redes de cooperación laboral y solidaridad mutua (tanto a nivel familiar como vecinal) imprescindibles para sacar adelante la fiesta, y cuya base se encuentra en la pertenencia compartida por todos los individuos que organizan la fiesta a un territorio intracomunitario específico ${ }^{31}$. Un territorio que, como hemos visto, adquiere

30 Se trata de un guiso con carne de pavo muy condimentado (el gran número de chiles quemados que lleva hace que su salsa sea de color negro), especialmente vinculado con las fiestas religiosas y que es muy apreciado en todo el ámbito maya yucateco. En la vertiente oriental de la Península recibe el nombre de «box janál» y, según Terán y Rasmussen (2005: 182), se trata de un plato cuyo origen es prehispánico.

31 Quintal et al. (2003a: 330) para el caso peninsular y Saúl Millán (2003) en un ensayo de carácter general sobre el área cultural mesoamericana, se han ocupado de estas «unidades intermedias» que existen en el interior de las comunidades indígenas. Ambos han remarcando el poco interés que han despertado este tipo de agrupaciones en las etnografías realizadas hasta la fecha. 
especial relevancia y se destaca del resto de los barrios de Nunkiní durante el periodo cronológico en el que transcurre la fiesta que sus habitantes dedican a su mecenas sagrado. De igual forma, todo lo anterior influye para generar entre los actores sociales que participan (bien como invitados, bien como organizadores) un sentimiento de pertenencia a ese espacio intracomunitario particular, cuyo principal referente simbólico se fija en la figura sagrada del santo que le da nombre, a través del programa mítico y ritual que le dedican sus vecinos. Programa ceremonial que recrea, a mucha menor escala, el sistema de la fiesta patronal que la comunidad como conjunto dedica a su santo principal.

\section{A modo de punto y seguido}

El incipiente estado en que se encuentran mis pesquisas sobre los barrios de Nunkiní a día de hoy, no me ha permitido más que esbozar aquí una ínfima parte de la complejidad que se esconde detrás de la conformación y el funcionamiento de estas unidades intermedias en el seno de la comunidad estudiada. Por ello, me he limitado aquí exclusivamente a referir el sustento que en la tradición oral local tiene el histórico antagonismo entre el norte y el sur, tratando de mostrar alguno de los acuerdos y desacuerdos que existen al respecto en la narrativa local. Sin embargo, falta aún por profundizar en cómo año con año dicha rivalidad se recrea, actualizándose, en celebraciones como la del carnaval, donde las comparsas de ambos rumbos (el norte y el sur) compiten por ser nombradas las mejores durante la fiesta del sábado de bando; mientras que los tradicionales «osos» de uno y otro barrio vengan las posibles afrentas que hubieran podido sufrir durante el año, amparados en el anonimato que les conceden las máscaras o los costales de soskil con que cubren sus rostros y cuerpos. Y es que la popular fiesta del carnaval que se vive en Nunkiní bien merece un artículo aparte, pues constituye un lugar paradigmático para acercarnos a los resquicios que todavía pervive en la población de la dualidad entre el norte y el sur, siendo esta tradicional fiesta de inversión el último reducto con el que cuentan los vecinos de ambos barrios para poder dilucidar sus diferencias, aún de formas no exentas de violencia. No en vano, hasta hace algo menos de dos décadas, por varios años San Román y San Marcelino celebraron por separado sus respectivos carnavales en las plazas de sus barrios. Durante este tiempo se revivieron en Nunkiní los enfrentamientos entre ambos bandos cada vez que un grupo de osos del barrio contrario trataba de penetrar en el propio. En este punto es interesante constatar como la narrativa en torno a este antagonismo entre los dos rumbos, cuyo máximo exponente sigue siendo la presencia de un cementerio en el norte y otro en el sur, se encuentra sometida a constantes cambios y reconfiguraciones, las cuales remiten a la cambiante realidad de la sociedad local de la cual no están exentos sus barrios.

Por su parte, profundizar en el funcionamiento de las ocho capillas (y sus respectivas sociedades) que funcionan a día de hoy dentro de la población, o en las peculiaridades que adoptan las celebraciones que se realizan en cada una de ellas, nos está permitiendo vislumbrar la presencia de otros factores de índole político, económico y de prestigio social en los que será preciso profundizar. Así, ahora que entramos en 
tiempos electorales, comienzan a ser frecuentes las visitas de personas que buscan ocupar la presidencia municipal a los encargados de las capillas y a los propios santos. Los candidatos buscan, en el primer caso, movilizar en su favor a los distintos grupos de parentesco extenso aglutinados en torno a las «sociedades» encargadas de festejar a los númenes barriales. Para ello ofrecen futuros apoyos para las capillas en forma de una puerta, una campana, miriñaques para las ventanas, ventiladores, pisos o cualquier otra cosa que pueda servir para mejorar el edificio. Con los santos intercambian promesas, a través de las cuales se comprometen a regalar un cerdo, pagar un conjunto de renombre o colmarlos de flores en su próxima celebración anual, siempre que sus deseos de llegar al Palacio Municipal se vean satisfechos.

Lo anterior no deja de ser una pequeña muestra de la importancia que en los últimos tiempos han ido adquiriendo las «sociedades» que se han ido creando en torno a las capillas de los barrios y el culto a los santos que las señorean desde sus altares. Algunas de estas agrupaciones de devotos merecen actualmente ser vistas como auténticos grupos de poder en el ámbito de los espacios de la población en los que se inscriben, en función de las extensas redes corporativas que han ido creando en torno a la participación conjunta de los vecinos en la celebración del santo del barrio, y al poder de convocatoria que han adquirido como colectivo. Así lo atestigua también el hecho de que desde hace unos pocos años la iglesia católica haya comenzado a arrimarse a las capillas, enviando emisarios procedentes de sus grupos apostólicos y realizando actividades semanales en sus instalaciones coincidiendo con las fechas más señaladas de la liturgia cristiana (Cuaresma, Corpus Christi, Semana Santa). Lo anterior no deja de ser un intento por parte de la jerarquía eclesiástica de extender su limitada influencia más allá de la iglesia y el centro de la población, e introducirse en aquellos espacios periféricos de la población que, hasta hace muy poco tiempo, constituían monopolios exclusivos de la religiosidad popular indígena ${ }^{32}$.

\section{Referencias bibliográficas}

BÁEz-Jorge, Félix

2008 Entre los naguales y los santos, $2^{\mathrm{a}}$ edición. Xalapa: Universidad Veracruzana.

BARTOlomé, Miguel Alberto

1988 La dinámica social de los mayas de Yucatán. Pasado y presente de la situación colonial. México: INI.

Bracamonte, Pedro y Gabriela Solís

1996 Espacios mayas de autonomía. México: UADY.

Burns, Allan F.

1995 Una época de milagros. Literatura oral del maya yucateco. Mérida: UADY.

Christian, William A.

1978 Religiosidad popular. Estudio antropológico en un valle español. Madrid: Tecnos.

32 Para un acercamiento más detallado al conflicto que se da actualmente entre la denominada religión o catolicismo popular y la religión oficial en el seno de las poblaciones indígenas de Mesoamérica, remito al interesado al lúcido trabajo que sobre este tema tiene Félix Báez-Jorge (2008). 
De Ángel García, David

2009 «Renovando el pacto con los dueños. Consideraciones etnográficas sobre las fiestas de san Diego y el Hanliko'ol en una comunidad maya de Campeche». Península 4 (1): 75-92.

2010 «El santo patrono y el Caballero de Fuego: miradas etnográficas sobre dos entidades poderosas de Nunkiní». Península 5 (1): 75-94.

FARRIS, Nancy

1992 La sociedad maya bajo el dominio español. La empresa colectiva de supervivencia. Madrid: Alianza Editorial.

FERNÁNDEZ REPETTO, Francisco

1995 «Celebrar a los santos: sistema de fiestas en el noroccidente de Yucatán». Alteridades 5 (9): 51-61.

Gutiérrez Estévez, Manuel

2001 «Pluralidad de perspectivas y sujetos en los géneros literarios de los mayas yucatecos», en La pluralidad y sus atributos, M. Dascal, M. Gutiérrez Estévez y J. de Salas, eds., pp. 59-90. Madrid: Biblioteca Nueva.

Instituto Nacional de Estadística, Geografía e Informática

2005 Campeche. Perfil sociodemográfico. XIII Censo general de población y vivienda 2005. Aguascalientes: INEGI.

LANDA, Fray Diego de

1978 Relación de las cosas de Yucatán. México: Editorial Porrúa.

Lizama, Jesús

2007 Estar en el mundo. Procesos culturales, estrategias económicas y dinámicas identitarias entre los mayas yucatecos. Mérida: CIESAS y Editorial Porrúa.

LóPez de Cogolludo, Fray Diego

1957 Historia de Yucatán (5ª . Ed. Facsimilar). México: Academia Literaria.

MiLLÁn, Saúl

2003 «Estructura social y comunidades indígenas: un balance prelimar», en La comunidad sin límites. Estructura social y organización comunitaria en las regiones indigenas de México, Vol. 1, S. Millán y J. Valle, coords., pp. 17-30. México: INAH.

QuezadA, Sergio

1993 Pueblos y caciques yucatecos 1550-1580. México: El Colegio de México.

1997 Los indios peninsulares 1550-1750. México: CIESAS e INI.

Quintal, Ella F., Juan Ramón Basterrachea, Fidencio Briceño, Martha Medina, Renée Petrich, Lourdes Rejón, Beatriz Repetto y Margarita Rosales

2003 a «Solares, rumbos y pueblos: organización social de los mayas peninsulares», en La comunidad sin límites. Estructura social y organización comunitaria en las regiones indígenas de México, Vol. 1, S. Millán y J. Valle, coords., pp. 291-382. México: INAH.

Quintal, Ella F., Juan R. Bastarrachea, Fidencio Briceño, Martha Medina, Beatriz Repetto, Lourdes Rejón, Margarita Rosales

2003b «U lu'umil maaya wíiniko'ob: la tierra de los mayas», en Diálogos con el territorio. Simbolizaciones sobre el espacio en las culturas indígenas de México, Vol. I, A.M. Barabás, coord., pp. 275-359. México: INAH. 